\title{
Social media as a risk communication tool following Typhoon Haiyan
}

\author{
Christine Tiffany Cool, , Marie Chantal Claravall, a Julie Lyn Hall, a Keisuke Taketani, a John Paul Zepeda, a \\ Monika Gehner ${ }^{b}$ and Olivia Lawe-Davies ${ }^{b}$ \\ Correspondence to Christine Tiffany Cool (email: christinecool@coolconsulting.net)
}

Problem: In the aftermath of Typhoon Haiyan, the World Health Organization (WHO) Representative Office in the Philippines had no social media presence to share timely, relevant public health information.

Context: Risk communication is essential to emergency management for public health message dissemination. As social media sites, such as Facebook, are popular in the Philippines, these were adopted for risk communication during the response to Haiyan.

Action and outcome: The WHO Representative Office in the Philippines established Facebook, Twitter and Instagram accounts. Thirty days after these social medial channels were established, a gradual increase in followers was observed. Facebook saw the largest increase in followers which occurred as posted content gradually evolved from general public health information to more pro-active public health intervention and preparedness messaging. This included information on key health interventions encouraging followers to adopt protective behaviours to mitigate public health threats that frequently occur after a disaster.

Lessons learnt: During the response to Haiyan, creating a social media presence, raising a follower base and developing meaningful messages and content was possible. This event underscored the importance of building a social media strategy in non-emergency times and supported the value of developing public health messages and content that both educates and interests the general public.

\section{PROBLEM}

Typhoon Haiyan affected over 16 million people in the Philippines with the health of people in affected areas threatened by outbreak-prone diseases and other public health risks. ${ }^{1}$ Infrastructure across all sectors was completely devastated and access to essential health-care services was limited. Mobilizing appropriate response measures took time. Therefore an emergency risk communication (ERC) plan was required to communicate with the public. As part of this ERC plan, social media was suggested as a way to enhance traditional ERC to the affected population.

Usually a social media strategy starts during nonemergency times. However, before Typhoon Haiyan, the World Health Organization (WHO) Representative Office in the Philippines had no social media presence for sharing timely, relevant public health information. The primary focus during the acute phase of a response is to rapidly release essential public health information to a large population. This paper therefore describes how social media was used to enhance traditional ERC and how a social media presence allowed for the broad and rapid dissemination of public health information in the response to Haiyan.

\section{CONTEXT}

Risk communication is an essential component of crisis or emergency management and is one of the core capacities required under the International Health Regulations. $^{2}$ In a disaster response, risk communication to affected communities ensures that interventions are evidence-based and include a range of capacities at each stage of the emergency (i.e. preparedness, response and recovery). It encourages informed decision-making, positive behaviour change and maintains the public's trust in those handling the emergency. ${ }^{3,4}$ 
Figure 1. Number of social media followers on WHO accounts by month after Typhoon Haiyan, November 2013 to January 2015

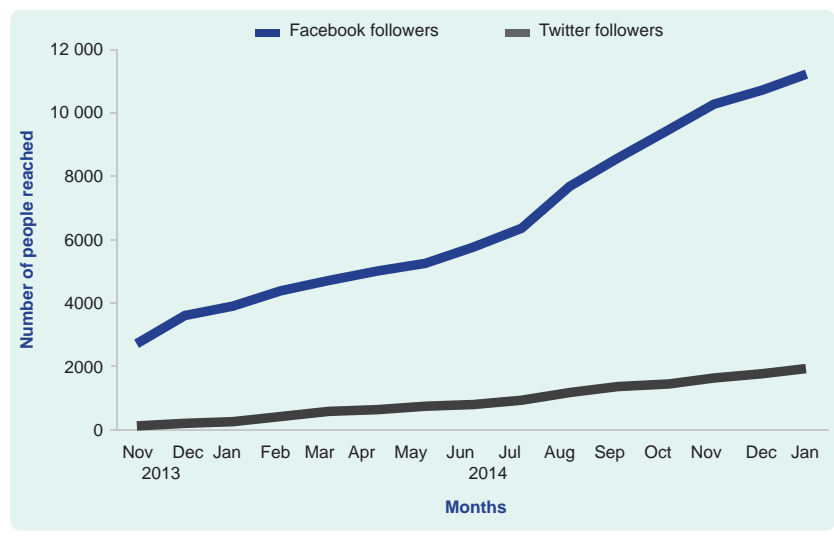

In recent times, social media has played an important role in public health message dissemination, particularly as a tool in emergency preparedness and response. ${ }^{5}$ Pro-active communication provides important health information and advice for the public to adopt protective behaviours that augment disease surveillance post-disaster, reduce public confusion and allow for better resource allocation. ${ }^{4}$

The Philippines, with a population of almost 100 million, had 34 million active Facebook users in $2014-97 \%$ of people living in urban areas and $69 \%$ of rural dwellers were accessing Facebook. ${ }^{6}$ Social media users were estimated to be spending on average four hours and 12 minutes on social media each day. ${ }^{6}$ The WHO Representative Office in the Philippines published bi-weekly health cluster bulletins as well as early warning alert and response reports on their website; however, the office did not have any other digital mechanism to disseminate information other than its website and traditional media channels.

\section{ACTION}

\section{Platform for information dissemination}

Typhoon Haiyan destroyed all telecommunications in the affected areas - there was no telephone, Internet or power until 20 November 2013 (12 days after the typhoon). By 27 November 2013 (19 days after the typhoon), a Facebook page for the WHO Representative Office in the Philippines was established; by 2 December 2013 (24 days after the typhoon), Twitter and Instagram accounts were also established by $\mathrm{WHO}$.
To assess the impact of these social media platforms, the monthly number of followers and posts were obtained from the Facebook and Twitter accounts between 27 November 2013 and 30 January 2015. The reach of a post on Facebook was defined as the number of views each post received in the first 28 days as reported on Facebook analytics. This included posts viewed by people on more than one device (e.g. desktop computer, mobile device and/or laptop). "Followers" were defined as a person or organization that 'liked' or 'followed' one of these social media accounts.

The Facebook account was prioritized as it had more users in the Philippines, particularly in rural areas, compared to other social media. Twitter only accounted for $40 \%$ of social media users in rural populations. ${ }^{6}$ There was an increase in the number of followers on both Facebook and Twitter, although this was more marked for Facebook (Figure 1). There was also an increase observed for the Instagram account (data not shown).

According to WHO policy, all social media posts and followers have to be generated organically. This policy posed a great challenge to the social media team as it had to rely on followers that actively sought out the WHO social media pages, which were being generated for the first time, rather than using mechanisms where content is placed in social media accounts. Because of this, the social media team had to figure out how to use agencies with an established social media presence, such as Health Cluster partners, health officials, local government and celebrities, to encourage their followers to keep up to date with WHO health responses and priorities for the typhoon-affected area without the help of paid social media advertisements.

\section{Shift in messages: Reaching affected populations}

The initial content of posts on Facebook provided information about the WHO emergency response and comprised mostly photos and text. As the risk communication needs evolved during the response, so too did the posts. Public health messages (e.g. that drinking boiled water was essential) were gradually replaced with messages encouraging the public to take protective actions against public health threats that commonly follow disasters. In July 2014, Typhoon Glenda made landfall in Manila, and so the social media message content post-Haiyan included preparation 
messages for Glenda as well. The presentation of content also changed, with more illustrative infographics showing people what to do; these resulted in further reach and more followers (Table 1).

As the content of social media became more informed by technical input from both $\mathrm{WHO}$ and the Department of Health, working collaboratively to align policy and practice with social media messaging, the number of people reached per post increased (Table 1). An infographic on immunization resulted in a $76 \%$ increase in people reached over two months; this infographic was seen by 3190 people over 28 days. An infographic on breastfeeding in disasters reached 9636 people within 28 days, compared to a photo and text that reached only 1354 people in the same time period.

The ERC strategy also relied on the collaboration of WHO with Health Cluster partners. During daily meetings, the needs of those in the affected areas were discussed along with the activities being undertaken. The social media outputs were also reported, some of which were disseminated with partners such as UNICEF and the Department of Health, for example the promotion of breastfeeding in disasters. This opportunity to collaborate with partners increased the social media coverage.

The social media team was able to track the performance of each post through the Facebook analytics tool which helped in identifying the type of content that gained the greatest reach. For example, the "Health at the Heart of Healing" campaign called for people to post a picture of themselves making a heart gesture with their hands to show support for those in affected areas. Within the first week of the campaign, 170 entries were distributed to all WHO hubs in the Typhoon Haiyan-affected regions. Participation in this campaign included Philippines government officials, Health Cluster partners, health officials, overseas Filipino workers and WHO staff in the Philippines and in the European Region and Region of the Americas. Traditional media reported on the social media campaign, featuring the health priorities in affected areas six months after the typhoon.

\section{LESSONS LEARNT}

As the ERC plan was developed during the response to an emergency, parameters for defining its success and evaluating the effectiveness of the strategy were not established. The importance of system evaluation was one of the primary lessons learnt. Evaluation is integral to determining the impact that communication interventions and activities have on behaviour change and the public's risk perception. It also determines whether the messages are being received, understood and adopted by target groups. WHO was only able to evaluate the social media campaign using the number of views and likes from the social media posts. Although post views increased, whether the content resulted in offline engagement could not be assessed. Evaluation has been added to the updated WHO ERC standard operating procedures for implementation in future emergencies.

Some ways to determine whether social media messaging resulted in offline engagement is to conduct a survey of offline behaviours, have response teams observe behaviours to see if they align with social media messages or to verify through media monitoring if any changes in risk perception or behaviour change had occurred in the affected areas. ${ }^{3}$

Another main lesson learnt was that a social media presence should be established during non-emergency periods. This would give the team more time to establish a follower base, test the content that was most engaging and develop and test evaluation mechanisms to track the effectiveness of activities and interventions. If these mechanisms were in place, whether online activity translated to offline engagement could be determined.

Since affected populations measure, in part, the effectiveness of an emergency response based on the amount of information they have access to at any given time, ${ }^{7}$ effective ERC and coordination among partners is crucial. As each partner has different priorities, different aspects of the response are emphasized through social media. Getting essential public health information to the affected population and ensuring alignment with both national and international partners was challenging. A mechanism to facilitate effective coordination with various partners should be implemented. Creating an ERC subgroup to meet after the daily Health Cluster meetings would allow partners to discuss the best way to address ERC priorities. 
Table 1. Thematic posts and reach by message, WHO Philippines Facebook page, 8 November 2013 to 8 November 2014

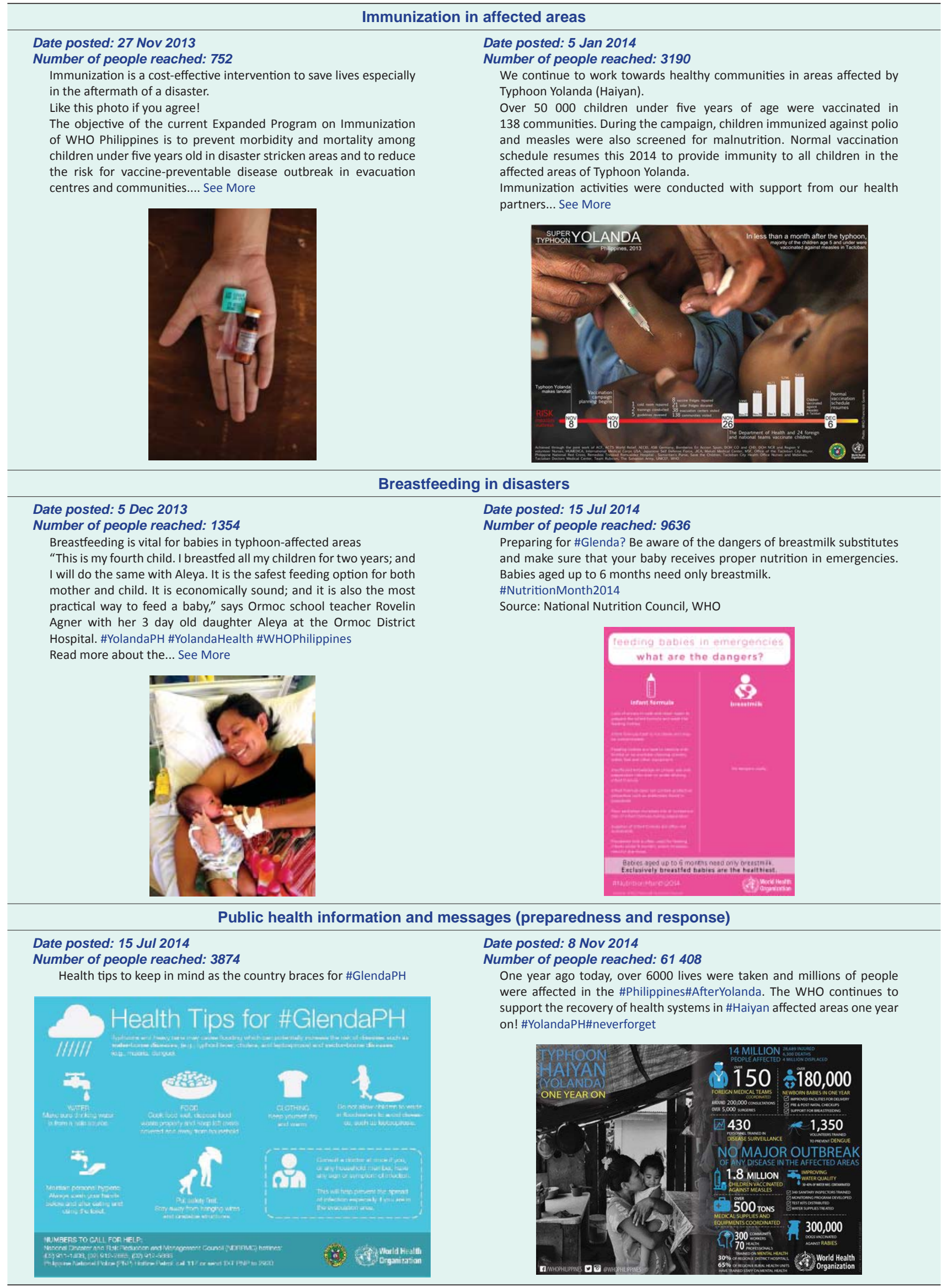




\section{CONCLUSION}

Social media was used for the first time by WHO in the Philippines as part of the ERC strategy in the response to Typhoon Haiyan. Creating a social media presence and organically generating a follower base was challenging, especially amidst such a large-scale humanitarian emergency. However, that the number of Facebook and Twitter followers increased over time suggested that these social media channels did allow for increased reach. Lessons learnt included having an evaluation strategy as part of the campaign, establishing the social media platforms during non-emergency times and improving collaboration between partners in the dissemination of social media content.

The power of social media is that users can leverage existing social networks to generate discussion or provide information on important issues, and it represents a costeffective tool for ERC. ${ }^{4}$ The ability to communicate in real-time enhances traditional ERC as it allows for rapid dissemination of public health information. Using social media in an emergency response should be part of all ERC strategies.

\section{Conflicts of interest}

None declared.

\section{Funding}

None.

\section{Acknowledgements}

We thank the following people for their input: Rachel Parry, Paulo Lyra, Nyka Alexander, Christina Banluta, Faith Kilford-Vorting, Ruth Foxwell, Aphaluck Bhatiasevi, Rosemarie Aguirre and Ivan Escartin. We also thank all those that responded to our campaign.

\section{References}

1. McPherson M, Counahan M, Hall JL. Responding to Typhoon Haiyan in the Philippines. Western Pacific Surveillance and Response Journal, 2015, 6(Suppl 1):1-4. doi:10.5365/ wpsar.2015.6.4.HYN_026

2. International Health Regulations implementation: ensuring effective responses to public health emergencies - strengthening risk communication capacities of national systems. Geneva, World Health Organization, 2012 (http://www.who.int/ihr/about/07 risk_communication.pdf, accessed 13 August 2015).

3. World Health Organization outbreak communication planning guide. Geneva, World Health Organization, 2008 (http://www. who.int/ihr/elibrary/WHOOutbreakCommsPlanngGuide.pdf, accessed 13 August 2015).

4. Merchant RM, Elmer S, Lurie N. Integrating social media into emergency-preparedness efforts. New England Journal of Medicine, 2011, 365:289-291. doi:10.1056/NEJMp1103591 pmid:21793742

5. Fung $\mathrm{IC}-\mathrm{H}$ et al. The use of social media in public health surveillance. Western Pacific Surveillance and Response Journal, 2015, 6(2):3-6. doi:10.5365/wpsar.2015.6.1.019

6. Kemp S. Social, Digital \& Mobile in APAC 2014. London, WeAreSocial, $2014 \quad$ (http://wearesocial.net/tag/philippines/, accessed 13 August 2015).

7. O'Malley P, Rainford J, Thompson A. Transparency during public health emergencies: from rhetoric to reality. Bulletin of the World Health Organization, 2009, 87:614-618. doi:10.2471/ BLT.08.056689 pmid:19705012 